\title{
Adverse childhood experiences among patients with substance use disorders at a referral psychiatric hospital in Kenya
}

\author{
Sarah Kanana Kiburi ${ }^{1 *}$ (D) Keneilwe Molebatsi ${ }^{2}$, Anne Obondo ${ }^{3}$ and Mary W. Kuria ${ }^{4}$
}

\begin{abstract}
Background: Substance use disorders are a major cause of health and social problems worldwide. Research evidence shows a strong graded relationship of adverse childhood experiences and substance use in adulthood. This study aimed at determining the prevalence of adverse childhood experiences and their association with substance use among patients with substance use disorders.

Method: The study used a descriptive cross-sectional design. A total of 134 patients aged 18 years and above receiving inpatient treatment for substance use disorders were recruited into the study. A mental state exam was done to rule out active psychopathology. Data on socio demographic variables, adverse childhood experiences (ACEs) and substance use was collected using Adverse Childhood Experiences International Questionnaire and The Alcohol, Smoking and Substance Involvement Screening Test respectively. Data was analysed using statistical package for social sciences (SPSS) version 20 for windows.

Results: Males accounted for the majority of the study participants ( $n=118,88.1 \%)$. Only $43.3 \%(n=58)$ of the participants had a family history of substance use disorder. The most frequently used substance was alcohol which was reported by $82.1 \%$ of the participants. Nearly $93 \%$ of the respondents had experienced at least one ACE and the most prevalent ACE was one or no parent which was reported by half of the respondents. The adverse childhood experiences significantly associated with current problematic substance use were; emotional abuse, having someone with mental illness in the household, physical abuse and physical neglect. Emotional abuse significantly predicted tobacco (A.O.R $=5.3$ (1.2-23.9)) and sedative (A.O.R $R=4.1(1.2-14.2))$ use. Childhood exposure to physical abuse was associated with cannabis use [A.O. $R=2.9$ (1.0-7.9)]. Experiencing five or more ACEs was associated with increased risk of using sedatives.

Conclusion: There is a high prevalence of adverse childhood experiences among patients with substance use disorders. Experiencing emotional abuse, having someone with mental illness in the household, physical abuse and physical neglect in childhood are risk factors of substance use disorders. ACEs screening and management should be incorporated in substance abuse prevention programs and policies.
\end{abstract}

Keywords: Adverse childhood experiences, Substance use disorders, Patients, Kenya

\footnotetext{
* Correspondence: sarahkiburi@gmail.com

'Department of Psychiatry, Mbagathi Hospital, Nairobi County, Nairobi P.O.

BOX 20725-00202, Kenya

Full list of author information is available at the end of the article
}

(c) The Author(s). 2018 Open Access This article is distributed under the terms of the Creative Commons Attribution 4.0 International License (http://creativecommons.org/licenses/by/4.0/), which permits unrestricted use, distribution, and reproduction in any medium, provided you give appropriate credit to the original author(s) and the source, provide a link to the Creative Commons license, and indicate if changes were made. The Creative Commons Public Domain Dedication waiver (http://creativecommons.org/publicdomain/zero/1.0/) applies to the data made available in this article, unless otherwise stated. 


\section{Background}

Childhood experiences have a tremendous impact on the development and prevalence of a wide range of health problems throughout a person's lifespan [1]. Early research conducted in this subject has been referred to as Adverse Childhood Experiences [2]. Adverse childhood experiences (ACEs) refer to stressful or traumatic events that children may suffer during early life [3]. Examples of such experiences include: various types of abuse, dysfunctional households, neglect and living in a violent community [4]. ACEs have been linked to substance use and behavioural disorders $[1,5]$; as the number of ACEs increases, so does the risk for these outcomes.

Exposure to repeated stress in children may result in disruption of their neurodevelopment $[1,6]$. This will result in impaired cognitive functioning. Over time, especially during adolescence the affected child tends to resort to negative coping mechanisms such as self-harm or substance use to cope with stressful life events $[7,8]$.

Substance use problems are prevalent and widespread worldwide. The World Health Organization (WHO) identified alcohol, tobacco and illicit drug use as among the top 20 risk factors for ill health. Globally $12.6 \%$ of deaths are attributable to alcohol, tobacco and illicit drug use. Tobacco alone causes almost one in eight deaths among adults aged 30 years and above. Substance use disorders account for $9 \%$ of disability-adjusted life year (DALYs) worldwide [3]. A clinical epidemiology study conducted among patients admitted at a psychiatric hospital in Kenya reported that $34.4 \%$ of admitted patients met the criteria for substance use disorders [9]. Another study conducted in rural and urban health centres in Kenya found that alcohol, tobacco, khat and cannabis were the commonest substances used in Kenya [10].

Research has demonstrated a strong positive association between ACEs and substance use disorders [11-14]. There is also evidence that presence of ACEs has a negative influence on management of patients with substance use disorders [15-17]. This indicates the need for screening of ACEs so that prevention measures could be put in place after identification of those at risk.

Most studies done on ACEs and their association with substance use are in developed countries $[18,19]$ with few studies done in developing countries on ACEs and their influence on various health outcomes. These include a study conducted in Nigeria on ACEs as risk factors for psychiatric illness including substance abuse. Another study conducted in four sub-Saharan African countries (Ghana, Burkina Faso, Uganda and Malawi) found an association between experience of ACEs and drunkenness in adolescence [14]. Most of the studies that have been done in Kenya on substance abuse focus on the prevalence of substance abuse without any association with risk factors. There is only one recently published study which studied
ACE association with alcohol consumption patterns among Kenyan mothers [20]. This creates a knowledge gap that needs attention. This study therefore aimed at establishing the prevalence of ACEs and their association with substance use among patients with substance use disorders. The data obtained will inform policy makers, and clinicians on ACEs and their association with substance use disorders. This will help in selection and implementation of policies, programs and strategies designed to address ACEs and include them in substance use prevention and treatment.

\section{Methods \\ Study design and duration}

This was a descriptive cross-sectional study. Data collection was done over a period of 2 months.

\section{Study setting and population}

This study was conducted at Mathari National Teaching and Referral Hospital (MNTRH) in Nairobi which is the only referral psychiatric hospital in Kenya. The study targeted inpatients with substance use disorders. To participate in the study patients had to be: aged 18 years and above, mentally stable at the time of the interview and able to give informed consent. The participants were drawn from the inpatient wards (male and female) and the drug rehabilitation unit. In the general wards patients on management for substance use disorders were identified from the admission record book in the ward.

\section{Procedure}

Study participants were recruited using convenience sampling method. All patients on management for substance use disorders were approached, screened for inclusion criteria and invited to participate until the desired sample size (134) was met. The researcher conducted a mental state exam to rule out active psychopathology (those with delusions, hallucinations and lacking insight). Those found to have active psychopathology were excluded.

Those who met the inclusion criteria and were willing to participate, were given a consent document to read and then after addressing their questions or concerns they were asked to sign an informed consent form. Data collection then proceeded by utilising ACE-IQ and ASSIST questionnaire for socio demographic data, adverse childhood experiences and substance use.

\section{Measures and instruments}

Adverse childhood experiences international questionnaire, (ACE- IQ)

The questionnaire was designed by WHO and Centres for Disease Control and Preventions (CDC) to measure ACEs in all countries and association between them and 
risk behaviours later in life [4]. The tool is currently being validated in several countries through trial implementation as part of broader health survey [21]. The ACE-IQ is designed for administering to people aged 18 years and above.

The questionnaire has a section that captures data on the socio-demographic variables of study participants, which include: age, sex, education level, ethnic group, marital status and employment. The researchers modified this section to leave out the section that asks about ethnic group and included a question about age at which participants first used substances of abuse. The ACEs screened by the questionnaire are: physical abuse, emotional abuse, sexual abuse, physical neglect, emotional neglect, household member treated violently, household member who was a substance abuser, household member with mental illness or suicidal, incarcerated household member, peer violence (bullying), community violence and collective violence. Two methods of analysis of ACE-IQ have been proposed [22]. For this study the frequency version of analysis was used. Total score was calculated by summing up the number of events a participant was exposed to.

ACE IQ has been found to be a reliable and valid index of the adverse childhood experience in Africa [23]. Another study in Germany described the ACE-IQ as a reliable, valid and economical screening tool for adverse childhood experiences [24].

\section{Alcohol, smoking and substance involvement screening test (ASSIST)}

The tool is used to screen for problematic or risky substance use. ASSIST consists of sections that have questions on tobacco, alcohol, cannabis, cocaine, amphetamine, inhalants, sedatives, hallucinogen, opioids and other drugs [25].

In validation studies done, ASSIST has shown good concurrent validity $(r=0.76-0.88, p \leq 0.001)$, good internal consistency $(\alpha=0.68-0.88)$ and ability to discriminate between gradation of abuse [26-28]. A validation study done on adolescents reported high validity with sensitivities of $95-100 \%$, specificities of $90-93 \%$ and area under the curve, AUC, 90-94\% [26].

\section{Data analysis}

Descriptive statistics was conducted to summarize socio-demographic characteristics, family history of mental illness and substance use. Chi-square/Fischer's exact tests was used to test for the heterogeneity between males and females. Prevalence rates and their 95\% Confidence interval was reported for each of the category of adverse childhood experience (ACEs); Alcohol and substance use (lifetime and current). Prevalence rates were used to describe exposure to different adverse childhood experiences among patients with substance use disorders. Adjusted odds ratio and 95\% confidence interval were obtained from logistic regression models that assessed the associations between each category of (ACE) and the common drugs and substances used. The number of ACEs, were summed for each person using Frequency version of analysis guidelines for analysing the ACE-IQ which ranged from 0 to 13; Analysis were repeated with the summed scores as ordinal variable $(0$, $1,2,3,4,5$ and $\geq 6$ ) or a dichotomous variable (Yes/No) with 0 experience as referent. Covariates in the models included; gender, educational level, employment status, marital status, family history of substance abuse and family history of mental illness.

\section{Results}

The socio-demographic characteristics of the participants are presented in Table 1. Majority of the participants were males (88.1\%). Most of the participants were aged between 31 and 40 years (33.6\%) and most reported to have first used drugs when they were between the ages of 16 and 20. Family history of substance abuse was reported by $43.3 \%$ of the participants and $15.7 \%$ reported family history of mental illness.

As depicted in Table 2 the most commonly reported ACE was one or no parent followed by household member treated violently. Males reported experiencing more ACEs compared to females.

Table 3 presents the results of the interrelatedness of ACEs, if a respondent was exposed to one of ACEs the probability of exposure to any additional category increased substantially. The median probability of exposure to any additional category given exposure to the first was 97\%; for any two additional categories, the median probability was $89 \%$.

Table 4 presents the results of prevalence of alcohol, tobacco and illicit drugs use in their lifetime and the current use. The most common substance used was alcohol which was being currently used by $82.1 \%$ of the participants. Less than a tenth $(9.7 \%)$ of the participants reported use of only a single substance with majority reporting use of at least 2 substances. As can be seen, the larger population of $26.9 \%$ had used 4 different substances within the past 3 months with $14.2 \%$ currently using more than 5 substances.

\section{Association between lifetime use of drugs and ACEs}

The ACEs were analysed against the lifetime use of substances so as to determine any association controlling for gender, educational level, employment and marital status, family history of substance abuse and family history of mental illness (Table 5).

Emotional abuse was found to be a significant predictor of using tobacco [A.O. $R=22.8(1.6-332.9)$ ]. 
Table 1 Socio-Demographic Characteristics by Gender

\begin{tabular}{|c|c|c|c|c|c|}
\hline Variable & Category & Overall $(N=134)$ & Females $(n=16)$ & Males $(n=118)$ & $P$-Value \\
\hline & & n (\%) & n (\%) & n (\%) & \\
\hline \multirow[t]{2}{*}{ Gender } & Female & $16(11.9)$ & - & - & - \\
\hline & Male & $118(88.1)$ & - & - & \\
\hline \multirow[t]{5}{*}{ Age in years } & 18-20 Years & $12(9.0)$ & $1(6.3)$ & $11(9.3)$ & 0.859 \\
\hline & 21-25 Years & $34(25.4)$ & $4(25.0)$ & $30(25.4)$ & \\
\hline & 26-30 Years & $26(19.4)$ & $3(18.8)$ & $23(19.5)$ & \\
\hline & 31-40 Years & 45 (33.6) & $7(43.8)$ & $38(32.2)$ & \\
\hline & Above 40 Years & $17(12.7)$ & $1(6.3)$ & $16(13.6)$ & \\
\hline \multirow[t]{3}{*}{ Age at first use } & 15 Years and below & $33(24.6)$ & $2(12.5)$ & $31(26.3)$ & 0.455 \\
\hline & $16-20$ Years & $67(50.0)$ & $10(62.5)$ & $57(48.3)$ & \\
\hline & 21 years and above & $34(25.4)$ & $4(25.0)$ & $30(25.4)$ & \\
\hline \multirow[t]{3}{*}{ Education level } & Primary and below & $35(26.1)$ & $10(62.5)$ & $25(21.2)$ & 0.002 \\
\hline & Secondary education & $41(30.6)$ & $3(18.8)$ & $38(32.2)$ & \\
\hline & Tertiary and above & $58(43.3)$ & $3(18.8)$ & $55(46.6)$ & \\
\hline \multirow[t]{2}{*}{ Employment status } & Unemployed & $31(23.1)$ & $3(18.8)$ & $28(23.7)$ & 0.763 \\
\hline & Employed & $103(76.9)$ & $13(81.3)$ & $90(76.3)$ & \\
\hline \multirow[t]{3}{*}{ Monthly net Income $(N=103)$} & Less than 20,000 & $49(47.6)$ & $8(61.5)$ & $41(45.6)$ & 0.485 \\
\hline & $20,001-35,000$ & 37 (35.9) & $4(30.8)$ & $33(36.7)$ & \\
\hline & Above 35,000 & $17(16.5)$ & $1(7.7)$ & $16(17.8)$ & \\
\hline \multirow[t]{3}{*}{ Marital Status } & Married & $44(32.8)$ & $3(18.8)$ & $41(34.7)$ & 0.466 \\
\hline & Divorced/ Separated/widowed & $25(18.7)$ & $3(18.8)$ & $22(18.6)$ & \\
\hline & Single & $65(48.5)$ & $10(62.5)$ & $55(46.6)$ & \\
\hline \multirow[t]{2}{*}{ Family history of substance use } & No & $76(56.7)$ & $10(62.5)$ & $66(55.9)$ & 0.789 \\
\hline & Yes & $58(43.3)$ & $6(37.5)$ & $52(44.1)$ & \\
\hline \multirow[t]{2}{*}{ Family history of mental illness } & No & $113(84.3)$ & $15(93.8)$ & $98(83.1)$ & 0.320 \\
\hline & Yes & $21(15.7)$ & $1(6.3)$ & $20(16.9)$ & \\
\hline
\end{tabular}

${ }^{\mathrm{a} C h i-s q u a r e / F i s c h e r ' s ~ e x a c t ~ t e s t ~ f o r ~ h e t e r o g e n e i t y ~ t e s t ~}$

Having a household member treated violently increased the risk of lifetime alcohol use [A.O.R $R=14.6$ (1.5140.8)]. Lifetime sedative use was found to be positively associated with physical abuse, emotional abuse and having someone with mental illness in the household.

Having one or no parent, physical neglect, violence were all found to be protective against lifetime use of khat.

\section{Association between current use of drugs and ACEs}

The ACEs were also analysed against the currently used substances so as to determine any association controlling for gender, educational level, employment and marital status, family history of substance abuse and family history of mental illness as depicted in Table 6.

Cannabis, tobacco and sedatives are the only substances which had significant positive correlation with experience of ACEs among the respondents. Having one or no parent was found to be protective against current use of khat.

\section{Discussion}

The majority of patients being treated for substance use disorders in the current study were males (88.1\%) which compares to previous studies $[9,29]$. This could be due to the cultural attitudes and negative stigma attached to females who use substances hence, females avoid reporting about substance use or seeking treatment. Half (50\%) of the respondents first used drugs when they were between the ages of 16 and 20. This is not surprising as substance use usually starts in adolescence due to peer pressure and curiosity leading to experimentation.

Alcohol, tobacco, cannabis and Khat were the most commonly used substances. Although, lifetime alcohol use was significantly associated with having been exposed to household member treated violently in childhood, there was no association found between current problematic use of alcohol and ACEs. Experiencing emotional abuse was found to be a significant predictor of problematic lifetime and/or current use of tobacco and sedatives. Surprisingly, experience of having one or 
Table 2 Prevalence and 95\% C.I of Categories of ACE and ACE Score by Gender

\begin{tabular}{|c|c|c|c|c|c|c|}
\hline \multirow[t]{2}{*}{ Category of ACE } & \multicolumn{2}{|c|}{ Overall $(N=134)$} & \multicolumn{2}{|c|}{ Females $(n=16)$} & \multicolumn{2}{|c|}{ Males $(n=118)$} \\
\hline & $n$ & Prevalence $(95 \%$ C.I) & $n$ & Prevalence (95\% C.I) & $n$ & Prevalence (95\% C.I) \\
\hline \multicolumn{7}{|l|}{ Abuse } \\
\hline Physical abuse & 31 & $23.1(16.4-29.9)$ & 3 & $18.8(0.0-37.5)$ & 28 & $23.7(16.1-31.4)$ \\
\hline Emotional abuse & 30 & $22.4(15.7-29.9)$ & 3 & $18.8(0.0-37.5)$ & 27 & $22.9(15.3-30.5)$ \\
\hline Contact sexual & 35 & $26.1(19.4-33.6)$ & 8 & $50.0(25.0-75.0)$ & 27 & $22.9(15.3-29.7)$ \\
\hline \multicolumn{7}{|l|}{ Family } \\
\hline Alcohol/drug user in household & 58 & $43.3(35.1-51.5)$ & 6 & $37.5(18.8-62.5)$ & 52 & $44.1(34.7-52.5)$ \\
\hline Incarcerated household member & 30 & $22.4(15.7-29.9)$ & 4 & $25.0(6.3-50.0)$ & 26 & $22.0(15.3-29.7)$ \\
\hline $\begin{array}{l}\text { Someone with mental illness } \\
\text { in household }\end{array}$ & 21 & $15.7(9.7-22.4)$ & 1 & $6.3(0.0-18.8)$ & 20 & $16.9(11.0-23.7)$ \\
\hline $\begin{array}{l}\text { Household member treated } \\
\text { violently }\end{array}$ & 66 & $49.3(40.3-58.2)$ & 7 & $43.8(18.8-68.8)$ & 59 & $50.0(41.5-59.3)$ \\
\hline One or no parent & 67 & $50.0(41.0-58.2)$ & 12 & $75.0(50.0-93.8)$ & 55 & $46.6(37.3-55.9)$ \\
\hline \multicolumn{7}{|l|}{ Parents/guardian } \\
\hline Emotional neglect & 53 & $39.6(30.6-48.5)$ & 6 & $37.5(12.5-62.5)$ & 47 & $39.8(30.5-48.3)$ \\
\hline Physical neglect & 16 & $11.9(6.7-17.2)$ & 2 & $12.5(0.0-31.3)$ & 14 & $11.9(6.8-17.8)$ \\
\hline Bullying & 17 & $12.7(7.5-18.7)$ & 0 & $0.0(0.0-0.0)$ & 17 & $14.4(8.5-20.3)$ \\
\hline \multicolumn{7}{|l|}{ Violence } \\
\hline Community violence & 41 & $30.6(23.1-38.8)$ & 4 & $25.0(6.3-50.0)$ & 37 & $31.4(22.9-40.7)$ \\
\hline Collective violence & 55 & $41.0(32.8-49.3)$ & 4 & $25.0(6.3-43.8)$ & 51 & $43.2(33.9-51.7)$ \\
\hline \multicolumn{7}{|l|}{ ACE Score } \\
\hline 0 & 10 & $7.5(3.7-11.9)$ & 2 & $12.5(0.0-31.3)$ & 8 & $6.8(2.5-11.9)$ \\
\hline 1 & 19 & $14.2(9.0-20.1)$ & 0 & $0.0(0.0-0.0)$ & 19 & $16.1(9.3-22.9)$ \\
\hline 2 & 21 & $15.7(9.7-21.6)$ & 2 & $12.5(0.0-31.3)$ & 19 & $16.1(10.2-22.9)$ \\
\hline 3 & 17 & $12.7(7.5-17.9)$ & 2 & $12.5(0.0-31.3)$ & 15 & $12.7(6.8-19.5)$ \\
\hline 4 & 18 & $13.4(8.2-19.4)$ & 4 & $25.0(6.3-50.0)$ & 14 & $11.9(6.8-17.8)$ \\
\hline 5 & 14 & $10.4(5.2-15.7)$ & 4 & $25.0(6.3-50.0)$ & 10 & $8.5(3.4-13.6)$ \\
\hline$>=6$ & 35 & $26.1(18.7-33.6)$ & 2 & $12.5(0.0-31.3)$ & 33 & $28.0(20.3-36.4)$ \\
\hline
\end{tabular}

no parent was found to be protective against current use of khat in this study. Sedative use was increased among participants who had experienced five or more ACEs.

Regarding the participant current use of substances; The most commonly used substances were alcohol $(82.1 \%)$, tobacco $(74.6 \%)$, cannabis $(56.7 \%)$ and khat $(46.3 \%)$ as has been demonstrated in earlier studies conducted in similar populations [10, 30]. Studies conducted in Kenya rural and urban health centres and Bugando hospital in Tanzania also found alcohol, tobacco, khat and cannabis to be the most frequently used substances $[10,30]$. The substances most frequently used by respondents in the three studies are readily available and cost less compared to others such as cocaine. This could explain why most participants preferred them over others. The current findings however differ with a study conducted by Ndetei at the same facility. In their study, the most common substances reported by participants were opioids, sedatives and stimulants [9]. The reason for the variance could be because currently MNTRH offers outpatient treatment for opioid use disorders therefore few patients with opioid use disorders are treated as in- patients.

Most of the participants in this study used more than one substance with less than a tenth (9.7\%) reporting use of only one substance. This agrees with the findings by a study in India where $91.9 \%$ of the participants reported to have poly-substance use.

Majority (92.5\%) of the participants reported experiencing at least one ACE. This compares to findings from a study conducted in Saudi Arabia, where 18\% of the participants reported no ACE exposure [31]. However, these rates are much higher than those from the ACE study in which $52 \%$ of the participants had experienced one or more ACEs [5]. The difference in the rates may be accounted for by the use of different questionnaires thereby difference in adversities screened for. The present study used the WHO Adverse childhood 


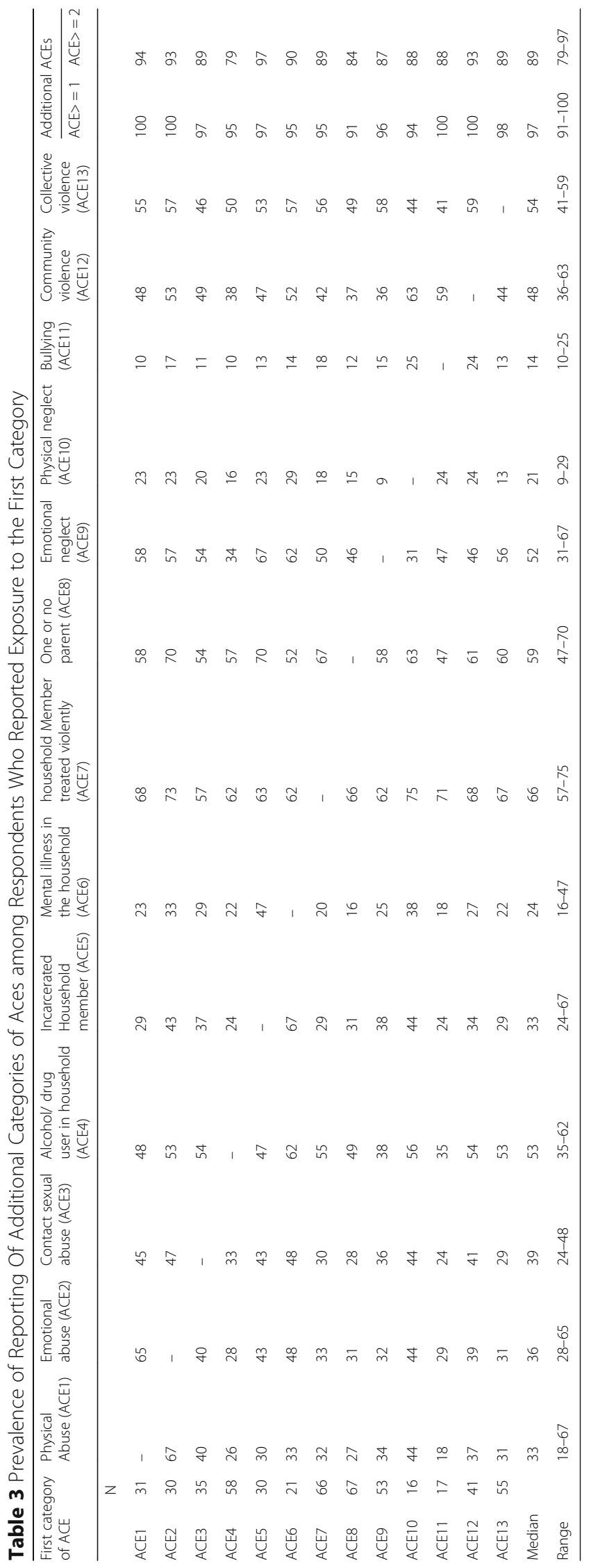


Table 4 Prevalence of drug use and number of drugs used by gender

\begin{tabular}{|c|c|c|c|c|c|c|}
\hline \multirow[t]{2}{*}{ Type of Drug } & \multicolumn{2}{|c|}{ Overall $(N=134)$} & \multicolumn{2}{|c|}{ Females $(n=16)$} & \multicolumn{2}{|c|}{ Males $(n=118)$} \\
\hline & $n$ & Prevalence (95\% C.I) & $n$ & Prevalence (95\% C.I) & $n$ & Prevalence (95\% C.I) \\
\hline \multicolumn{7}{|c|}{ Lifetime use (Ever used) } \\
\hline Tobacco & 113 & $84.3(78.4-90.3)$ & 14 & $87.5(68.8-100.0)$ & 99 & $83.9(77.1-90.7)$ \\
\hline Alcohol & 123 & $91.8(87.3-96.3)$ & 14 & $87.5(68.8-100.0)$ & 109 & $92.4(87.3-97.4)$ \\
\hline Cannabis & 86 & $64.2(56.0-72.4)$ & 13 & $81.3(62.5-100.0)$ & 73 & $61.9(53.4-70.3)$ \\
\hline Cocaine & 7 & $5.2(2.2-9.0)$ & 2 & $12.5(0.0-31.3)$ & 5 & $4.2(0.8-8.5)$ \\
\hline Amphetamine & 4 & $3.0(0.7-6.0)$ & 0 & $0.0(0.0-0.0)$ & 4 & $3.4(0.8-6.8)$ \\
\hline Inhalants & 7 & $5.2(1.5-9.0)$ & 0 & $0.0(0.0-0.0)$ & 7 & $5.9(1.7-10.2)$ \\
\hline Sedatives & 30 & $22.4(15.7-29.1)$ & 4 & $25.0(6.3-50.0)$ & 26 & $22.0(15.3-30.5)$ \\
\hline Hallucinogen & 5 & $3.7(0.7-7.4)$ & 1 & $6.3(0.0-18.8)$ & 4 & $3.4(0.8-6.8)$ \\
\hline Opioids & 11 & $8.2(3.7-13.4)$ & 5 & $31.3(12.5-56.3)$ & 6 & $5.1(1.7-9.3)$ \\
\hline Khat & 74 & $55.2(47.0-64.2)$ & 11 & $68.8(43.8-93.8)$ & 63 & $53.4(44.9-61.9)$ \\
\hline \multicolumn{7}{|c|}{ Current use (Past 3 months) } \\
\hline Tobacco & 100 & $74.6(67.2-82.1)$ & 13 & $81.3(62.5-100.0)$ & 87 & $73.7(66.1-81.4)$ \\
\hline Alcohol & 110 & $82.1(75.4-88.8)$ & 13 & $81.3(62.5-100.0)$ & 97 & $82.2(74.6-89.0)$ \\
\hline Cannabis & 76 & $56.7(49.3-64.9)$ & 11 & $68.8(43.8-93.6)$ & 65 & $55.1(46.6-64.4)$ \\
\hline Cocaine & 5 & $3.7(0.7-7.5)$ & 0 & $0.0(0.0-0.0)$ & 5 & $4.2(0.8-8.5)$ \\
\hline Amphetamine & 3 & $2.2(0.0-5.2)$ & 0 & $0.0(0.0-0.0)$ & 3 & $2.5(0.0-5.9)$ \\
\hline Inhalants & 5 & $3.7(0.7-7.4)$ & 0 & $0.0(0.0-0.0)$ & 5 & $4.2(0.8-7.6)$ \\
\hline Sedatives & 19 & $14.2(8.2-20.1)$ & 1 & $6.3(0.0-18.8)$ & 18 & $15.3(9.3-22.0)$ \\
\hline Hallucinogen & 3 & $2.2(0.0-4.5)$ & 0 & $0.0(0.0-0.0)$ & 3 & $2.5(0.0-5.9)$ \\
\hline Opioids & 6 & $4.5(1.5-8.2)$ & 3 & $18.8(0.0-37.5)$ & 3 & $2.5(0.0-5.9)$ \\
\hline Khat & 62 & $46.3(38.1-55.2)$ & 9 & $56.3(31.3-81.3)$ & 53 & $44.9(36.4-53.4)$ \\
\hline \multicolumn{7}{|c|}{ Number of drugs currently using } \\
\hline 1.00 & 13 & $9.7(5.2-14.9)$ & 2 & $12.5(0.0-31.3)$ & 11 & $9.3(4.2-15.3)$ \\
\hline 2.00 & 31 & $23.1(15.7-29.9)$ & 5 & $31.3(12.5-56.3)$ & 26 & $22.0(14.4-29.7)$ \\
\hline 3.00 & 35 & $26.1(18.7-34.3)$ & 0 & $0.0(0.0-0.0)$ & 35 & $29.7(21.2-38.1)$ \\
\hline 4.00 & 36 & $26.9(20.1-34.3)$ & 6 & $37.5(12.5-62.5)$ & 30 & $25.4(17.8-33.1)$ \\
\hline 5 and Above & 19 & $14.2(9.0-20.1)$ & 3 & $18.8(0.0-43.6)$ & 16 & $13.6(7.6-19.5)$ \\
\hline
\end{tabular}

experiences international questionnaire whereas the ACE study used the ACE Study questionnaire which was constructed with questions from previously published surveys. Differences in prevalence estimates may also reflect variances brought about by different study settings i.e. Africa and non-African countries. Social factors will have a bearing on the occurrence of adverse childhood experiences and cultural expectations may determine which events individuals would consider as being adverse. The World Mental Health study, found that only $38.8 \%$ of the participants reported having experienced any ACE [32]. The lower prevalence could be explained by the different study populations; hospital based in the current study versus general population in the World Mental Health Study. Inpatients with substance use disorders are more likely to have experienced ACEs compared to the general population $[11,12]$.
Of those who reported experiencing any ACE majority (78.3\%) reported more than one ACE. These results are comparable to previous studies [5, 31]. In the ACE study by Felitti and colleagues, $16 \%$ reported experiencing four or more ACEs [5]. Almuneef found that 32\% of respondents reported four or more ACEs [31]. The reason for this could be that exposure to one ACE has been found to increase the likelihood of experiencing other childhood adversities [13, 33], this is also reflected in the current study.

The most commonly reported ACE was one or no parent which was reported by half $(50 \%)$ of the respondents followed by household member treated violently (49\%). This is different from the findings in the original ACE study where the commonest ACEs reported were physical abuse and substance abuse by household member (both reported by $28 \%$ ) followed by sexual abuse 
Table 5 Prevalence and Adjusted Odds Ratio ${ }^{a}$ of Lifetime Use of Drugs by Category of ACE

\begin{tabular}{|c|c|c|c|c|c|c|c|}
\hline Type of ACE & & $\mathrm{N}$ & TOBACCOA.O.R & ALCOHOLA.O.R & CANNABISA.O.R & KHATA.O.R & SEDATIVESA.O.R \\
\hline \multirow[t]{2}{*}{ Physical abuse } & No & 103 & 1 (Ref.) & 1 (Ref.) & 1 (Ref.) & 1 (Ref.) & 1 (Ref.) \\
\hline & Yes & 31 & $1.4(0.4-5.7)$ & $5.6(0.6-56.9)$ & $2.5(0.9-7.1)$ & $1.2(0.5-3.0)$ & $3.9(1.4-11.2)$ \\
\hline \multirow[t]{2}{*}{ Emotional abuse } & No & 104 & 1 (Ref.) & 1 (Ref.) & 1 (Ref.) & 1 (Ref.) & 1 (Ref.) \\
\hline & Yes & 30 & $22.8(1.6-332.9)$ & $5.0(0.5-51.7)$ & $1.9(0.6-5.6)$ & $1.0(0.4-2.5)$ & $3.0(1.0-9.1)^{b}$ \\
\hline \multirow[t]{2}{*}{ Contact sexual abuse } & No & 99 & 1 (Ref.) & 1 (Ref.) & 1 (Ref.) & 1 (Ref.) & 1 (Ref.) \\
\hline & Yes & 35 & $1.1(0.3-4.3)$ & $1.2(0.2-7.4)$ & $1.1(0.4-3.2)$ & $0.7(0.3-1.7)$ & $1.7(0.6-5.1)$ \\
\hline \multirow{2}{*}{$\begin{array}{l}\text { Alcohol/drug user in } \\
\text { household }\end{array}$} & No & 76 & 1 (Ref.) & 1 (Ref.) & 1 (Ref.) & 1 (Ref.) & 1 (Ref.) \\
\hline & Yes & 58 & $1.8(0.6-5.9)$ & $1.3(0.3-5.7)$ & $0.8(0.4-1.9)$ & $2.0(0.9-4.4)$ & $0.7(0.3-1.7)$ \\
\hline \multirow{2}{*}{$\begin{array}{l}\text { Incarcerated household } \\
\text { member }\end{array}$} & No & 104 & 1 (Ref.) & 1 (Ref.) & 1 (Ref.) & 1 (Ref.) & 1 (Ref.) \\
\hline & Yes & 30 & $0.9(0.2-4.5)$ & $0.9(0.1-5.6)$ & $0.9(0.3-2.6)$ & $0.6(0.2-1.8)$ & $3.0(0.9-10.0)$ \\
\hline \multirow{2}{*}{$\begin{array}{l}\text { Someone with mental } \\
\text { illness in household }\end{array}$} & No & 113 & 1 (Ref.) & 1 (Ref.) & 1 (Ref.) & 1 (Ref.) & 1 (Ref.) \\
\hline & Yes & 21 & UD & $2.2(0.2-23.5)$ & $1.3(0.4-4.1)$ & $2.1(0.7-6.6)$ & $3.0(1.0-9.1)$ \\
\hline \multirow{2}{*}{$\begin{array}{l}\text { Household member } \\
\text { treated violently }\end{array}$} & No & 68 & 1 (Ref.) & 1 (Ref.) & 1 (Ref.) & 1 (Ref.) & 1 (Ref.) \\
\hline & Yes & 66 & $3.6(1.0-12.8)^{b}$ & $14.6(1.5-140.8)$ & $0.6(0.3-1.4)$ & $0.8(0.4-1.8)$ & $2.0(0.8-5.2)$ \\
\hline \multirow[t]{2}{*}{ One or no parent } & No & 67 & 1 (Ref.) & 1 (Ref.) & 1 (Ref.) & 1 (Ref.) & 1 (Ref.) \\
\hline & Yes & 67 & $0.7(0.2-2.1)$ & $1.2(0.3-5.1)$ & $0.5(0.2-1.1)$ & $0.4(0.2-0.9)$ & $1.9(0.7-5.2)$ \\
\hline \multirow[t]{2}{*}{ Emotional neglect } & No & 81 & 1 (Ref.) & 1 (Ref.) & 1 (Ref.) & 1 (Ref.) & 1 (Ref.) \\
\hline & Yes & 53 & $1.0(0.3-3.4)$ & $3.0(0.5-16.6)$ & $1.6(0.7-3.8)$ & $1.1(0.5-2.5)$ & $1.9(0.7-4.7)$ \\
\hline \multirow[t]{2}{*}{ Physical neglect } & No & 118 & 1 (Ref.) & 1 (Ref.) & 1 (Ref.) & 1 (Ref.) & 1 (Ref.) \\
\hline & Yes & 16 & UD & $0.2(0.0-1.1)$ & $0.6(0.2-2.3)$ & $0.3(0.1-1.0)^{b}$ & $2.1(0.6-8.4)$ \\
\hline \multirow[t]{2}{*}{ Bullying } & No & 117 & 1 (Ref.) & 1 (Ref.) & 1 (Ref.) & 1 (Ref.) & 1 (Ref.) \\
\hline & Yes & 17 & UD & $1.7(0.2-17.3)$ & $0.9(0.3-3.0)$ & $0.9(0.3-2.8)$ & $0.3(0.1-2.0)$ \\
\hline \multirow[t]{2}{*}{ Community violence } & No & 93 & 1 (Ref.) & 1 (Ref.) & 1 (Ref.) & 1 (Ref.) & 1 (Ref.) \\
\hline & Yes & 41 & $4.2(0.8-22.3)$ & $7.0(0.7-67.8)$ & $1.7(0.7-4.5)$ & $0.3(0.1-0.8)$ & $1.3(0.5-3.5)$ \\
\hline \multirow[t]{2}{*}{ Collective violence } & No & 79 & 1 (Ref.) & 1 (Ref.) & 1 (Ref.) & 1 (Ref.) & 1 (Ref.) \\
\hline & Yes & 55 & $1.1(0.4-3.5)$ & $1.6(0.4-6.9)$ & $0.8(0.4-1.9)$ & $0.4(0.2-0.9)$ & $2.5(1.0-6.3)$ \\
\hline
\end{tabular}

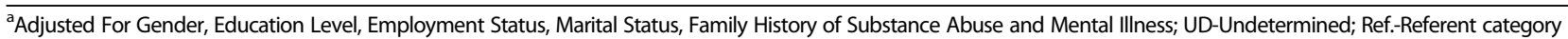

${ }^{\mathrm{b}}$ The values are more than 1.0 , only rounded off to one decimal place for uniformity

(reported by 21\%). The major differences in occurrence of ACE were those ACEs related to violence (community/collective violence and household member treated violently). The reason for this could be that the Felitti study did not assess for community or collective violence [5].

There were varied prevalence of ACEs by gender, however, in general males reported more ACEs as compared to females. This is also similar to findings in other ACE studies $[5,31]$. The reasons for this could be that the number of females in the study was less than that of males. The other reason could be because most cultures are girl-sensitive; during childhood females tend to be protected from violent occurrences in the community than male children. Conversely, females could be reluctant to report adversity due to cultural reasons. Among the abuse ACEs males reported more physical and emotional abuse compared to females, while females reported more of contact sexual abuse.
Although there was no association between current alcohol use and ACEs, lifetime alcohol use was significantly associated with having been exposed to household member treated violently. This finding compares with results reported in earlier studies where the prevalence of alcoholism was higher among patients who reported parental alcohol use [33]. Other studies have also shown alcohol use to be associated with physical and sexual abuse and community violence $[11,14,18]$.

Childhood exposure to emotional abuse increased the risk for lifetime tobacco use and current tobacco use by 22.8 and 5.3 times respectively. Tobacco use was also significantly associated with individuals who had been exposed to household member treated violently where they were about 4 times more likely to smoke tobacco in their lifetime. Having someone with mental illness in the household, increased risk of current tobacco use by five times. This is similar to findings by Anda and colleagues who reported an association between ACEs and early 
Table 6 Prevalence and Adjusted Odds Ratio ${ }^{a}$ Of Current Use of Drugs by Category of ACE

\begin{tabular}{|c|c|c|c|c|c|c|c|}
\hline \multirow[t]{2}{*}{ Type of ACE } & \multirow[t]{2}{*}{ Category } & \multirow[t]{2}{*}{ n (\%) } & \multirow{2}{*}{$\begin{array}{l}\text { Tobacco } \\
\text { A.O.R }\end{array}$} & \multirow{2}{*}{$\begin{array}{l}\text { Alcohol } \\
\text { A.O.R }\end{array}$} & \multirow{2}{*}{$\begin{array}{l}\text { Cannabis } \\
\text { A.O.R }\end{array}$} & \multirow{2}{*}{$\begin{array}{l}\text { Sedatives } \\
\text { A.O.R }\end{array}$} & \multirow{2}{*}{$\begin{array}{l}\text { Khat } \\
\text { A.O.R }\end{array}$} \\
\hline & & & & & & & \\
\hline \multirow[t]{2}{*}{ Physical abuse } & No & $103(76.9)$ & 1 (Ref) & 1 (Ref) & 1 (Ref) & 1 (Ref) & 1 (Ref) \\
\hline & Yes & $31(23.1)$ & $1.0(0.3-2.9)$ & $1.1(0.4-3.4)$ & $2.9(1.0-7.9)^{b}$ & $2.6(0.8-8.4)$ & $0.6(0.2-1.7)$ \\
\hline \multirow[t]{2}{*}{ Emotional abuse } & No & 104 (77.6) & 1 (Ref) & 1 (Ref) & 1 (Ref) & 1 (Ref) & 1 (Ref) \\
\hline & Yes & $30(22.4)$ & $5.3(1.2-23.9)$ & $0.8(0.3-2.5)$ & $2.5(0.9-7.0)$ & $4.1(1.2-14.2)$ & $0.5(0.2-1.5)$ \\
\hline \multirow[t]{2}{*}{ Contact sexual abuse } & No & 99 (73.9) & 1 (Ref) & 1 (Ref) & 1 (Ref) & 1 (Ref) & 1 (Ref) \\
\hline & Yes & $35(26.1)$ & $0.7(0.2-2.0)$ & $0.6(0.2-1.8)$ & $1.8(0.7-5.0)$ & $1.6(0.5-5.5)$ & $1.0(0.4-2.5)$ \\
\hline \multirow{2}{*}{$\begin{array}{l}\text { Alcohol/drug user in } \\
\text { household }\end{array}$} & No & $76(56.7)$ & 1 (Ref) & 1 (Ref) & 1 (Ref) & 1 (Ref) & 1 (Ref) \\
\hline & Yes & $58(43.3)$ & $1.1(0.4-2.7)$ & $0.8(0.3-2.1)$ & $1.2(0.6-2.7)$ & $0.8(0.3-2.2)$ & $2.1(0.9-4.9)$ \\
\hline \multirow{2}{*}{$\begin{array}{l}\text { Incarcerated household } \\
\text { member }\end{array}$} & No & 104 (77.6) & 1 (Ref) & 1 (Ref) & 1 (Ref) & 1 (Ref) & 1 (Ref) \\
\hline & Yes & $30(22.4)$ & $1.5(0.4-5.7)$ & $0.5(0.2-1.7)$ & $1.1(0.4-3.2)$ & $2.3(0.5-10.2)$ & $0.9(0.3-2.6)$ \\
\hline \multirow{2}{*}{$\begin{array}{l}\text { Someone with mental } \\
\text { illness in household }\end{array}$} & No & $113(84.3)$ & 1 (Ref) & 1 (Ref) & 1 (Ref) & 1 (Ref) & 1 (Ref) \\
\hline & Yes & $21(15.7)$ & $5.5(1.0-28.8)^{b}$ & $0.5(0.2-1.6)$ & $0.9(0.3-2.5)$ & $1.6(0.5-5.8)$ & $2.4(0.8-7.5)$ \\
\hline \multirow{2}{*}{$\begin{array}{l}\text { Household member } \\
\text { treated violently }\end{array}$} & No & $68(50.7)$ & 1 (Ref) & 1 (Ref) & 1 (Ref) & 1 (Ref) & 1 (Ref) \\
\hline & Yes & $66(49.3)$ & $2.1(0.8-5.5)$ & $2.2(0.8-6.2)$ & $0.7(0.3-1.6)$ & $1.7(0.6-5.2)$ & $0.6(0.3-1.3)$ \\
\hline \multirow[t]{2}{*}{ One or no parent } & No & $67(50.0)$ & 1 (Ref) & 1 (Ref) & 1 (Ref) & 1 (Ref) & 1 (Ref) \\
\hline & Yes & $67(50.0)$ & $1.0(0.4-2.5)$ & $0.9(0.3-2.4)$ & $0.5(0.2-1.0)$ & $2.2(0.7-6.7)$ & $0.3(0.1-0.8)$ \\
\hline \multirow[t]{2}{*}{ Emotional neglect } & No & $81(60.4)$ & 1 (Ref) & 1 (Ref) & 1 (Ref) & 1 (Ref) & 1 (Ref) \\
\hline & Yes & 53 (39.6) & $1.0(0.4-2.6)$ & $1.1(0.4-2.9)$ & $1.1(0.5-2.5)$ & $2.4(0.8-7.1)$ & $0.9(0.4-2.0)$ \\
\hline \multirow[t]{2}{*}{ Physical neglect } & No & $118(88.1)$ & 1 (Ref) & 1 (Ref) & 1 (Ref) & 1 (Ref) & 1 (Ref) \\
\hline & Yes & 16(11.9) & $5.7(0.6-50.0)$ & $0.4(0.1-1.6)$ & $0.9(0.3-3.3)$ & $4.9(1.0-23.2)^{b}$ & $0.5(0.1-1.8)$ \\
\hline \multirow[t]{2}{*}{ Bullying } & No & $117(87.3)$ & 1 (Ref) & 1 (Ref) & 1 (Ref) & 1 (Ref) & 1 (Ref) \\
\hline & Yes & $17(12.7)$ & $1.8(0.4-7.8)$ & $0.4(0.1-1.6)$ & $0.7(0.2-2.2)$ & $0.0(0.0-)$ & $0.7(0.2-2.4)$ \\
\hline \multirow[t]{2}{*}{ Community violence } & No & $93(69.4)$ & 1 (Ref) & 1 (Ref) & 1 (Ref) & 1 (Ref) & 1 (Ref) \\
\hline & Yes & 41 (30.6) & $1.8(0.6-5.4)$ & $1.6(0.5-5.0)$ & $2.2(0.9-5.5)$ & $1.1(0.3-3.5)$ & $0.5(0.2-1.2)$ \\
\hline \multirow[t]{2}{*}{ Collective violence } & No & $79(59.0)$ & 1 (Ref) & 1 (Ref) & 1 (Ref) & 1 (Ref) & 1 (Ref) \\
\hline & Yes & $55(41.0)$ & $1.1(0.4-2.7)$ & $2.4(0.8-6.9)$ & $1.2(0.5-2.6)$ & $1.7(0.6-4.9)$ & $0.5(0.2-1.1)$ \\
\hline
\end{tabular}

${ }^{a}$ Adjusted For Gender, Education Level, Employment Status, Marital Status, Family History of Substance Abuse and Mental Illness; UD-Undetermined; Ref.-Referent category

${ }^{\mathrm{b}}$ The values are more than 1.0 , only that it was rounded off to one decimal place

initiation of smoking [34]. Finding from another study stated that exposure to ACEs increased risk of continued smoking and heavy smoking in adulthood [35]. The mood elevating properties of nicotine may also explain why participants smoked to cope with emotional abuse and caregiver burden which may be a consequence of taking care of the mentally ill patient in the household.

Physical abuse positively predicted current use of cannabis which is comparable to previous studies [36, 37]. In a cohort study conducted by Alemu and colleagues, exposure to physical abuse was found to predict cannabis dependence $(\mathrm{AOR}=2.81)$. Other experiences associated with cannabis dependence were emotional abuse and neglect [37]. In another study exposure to childhood sexual abuse but not childhood physical abuse was found to increase risk for cannabis abuse or dependence. The authors reported this as an unexpected finding [36]. The difference in the methodologies between the two studies may have contributed to this variation in findings.

Unexpectedly, contrary to previous studies [38] being exposed to violence, physical neglect and having one or no parent were found to be protective against using lifetime and/or current use of Khat in the current study. A study conducted among Somali refugees found exposure to traumatic experiences to predict khat usage [38]. Somali refugees who used khat screened positive for post-traumatic stress disorder. The diagnosis could have been an effect modifier which explains the variance with the current study. The different study designs: case control study among Somali refugees and descriptive cross-sectional in our study may also explain the different findings. Factors such as resilience, societal norms and coping strategies determine how one responds to adversities. None of the compared studies measured 
these factors which might also explain the variance in the findings.

We found no significant differences between the number of ACEs experienced and tobacco, alcohol, cannabis and khat use. However those who had experienced 5 ACEs were 15 times more likely to use sedatives as compared to those who had not experienced any form of ACEs. This is not surprising as high scores of ACEs have been linked to increased utilization of psychotropic medications such as anxiolytics in earlier studies [39]. Exposure to moderate or severe ACEs has been associated with a more disturbed sleep amongst patients with insomnia [40] which may explain the increased usage of sedatives among the group.

\section{Limitations}

Over-reporting or under-reporting cannot be totally ruled out as a result of the use of self-report questionnaires. The data collected was retrospective which may have led to recall bias. Convenience sampling may result in sampling error and limits the generalizability of the findings beyond the sample. Effect modifiers which could alter the association of ACEs and substance use such as resilience and comorbid psychiatric illness were not measured in the study. The study was hospital based hence data collected was on patients who were admitted leaving out other patients with substance use disorders who may not be admitted. Therefore these findings may not be representation of all patients with substance use disorders.

\section{Conclusions and recommendations}

There is a high prevalence of adverse childhood experiences among patients on treatment for substance use disorders. Early screening and prevention of ACEs could be of importance to reduce their effect and help in management of patients.

Alcohol, tobacco, cannabis and khat are the most commonly used substances. This could be due to easy availability and less cost of the above mentioned substances compared to other substances of abuse. The findings are important in providing guidance on where to focus treatment and prevention strategies for substance use.

The most commonly reported ACE was one or no parent and household member treated violently. Exposure to household member treated violently and emotional abuse were significantly associated with use of substances. This could form a basis to more focused studies to establish the relationship of the above ACEs and substance use disorders.

Further to the findings of this study, we recommend further studies on ACEs in different regions of the country in different settings (community and clinical) as well as comparison of ACE prevalence in general population and those with adverse health outcomes such as substance use disorders. The findings may be used to inform policies on prevention and management of substance use disorders.

The findings of this study highlight the need to address the high prevalence and consequences of childhood traumatic stressors.

\section{Abbreviations}

ACE-IQ: Adverse Childhood experiences-International Questionnaire;

ACEs: Adverse childhood experiences; ASSIST: Alcohol and substance involvement screening tool; CDC: Centers for disease control and prevention; DALY: Disability adjusted life years; MNTRH: Mathari national teaching and referral hospital; WHO: World health organization

\section{Acknowledgements}

We acknowledge Isaiah Achini for assistance with editing the proposal for this research project and his comments. We are also grateful to Albert Tele for his input in data analysis.

\section{Availability of data and materials}

All data generated and analysed during the study are available from the corresponding author on reasonable request.

\section{Authors' contributions}

SKK made substantial contributions to conception, design, acquisition of data, interpretation of data and drafting the manuscript. KM was involved in interpretation of data, drafting the manuscript and revising it critically for important intellectual content; SKK, KM, AO, MWK revised the manuscript and gave final approval of the version to be published.

\section{Ethics approval and consent to participate}

The study was performed in accordance with the Declaration of Helsinki. Ethical approval was obtained from Kenyatta National Hospital and University of Nairobi Research Ethics Committee. Clearance was obtained from Mathari National and Teaching Referral Hospital research committee to undertake the study. Participation in the study was voluntary and both verbal and written informed consent were obtained from participants prior to data collection.

\section{Competing interests}

The authors declare that they have no competing interests.

\section{Publisher's Note}

Springer Nature remains neutral with regard to jurisdictional claims in published maps and institutional affiliations.

\section{Author details}

${ }^{1}$ Department of Psychiatry, Mbagathi Hospital, Nairobi County, Nairobi P.O. BOX 20725-00202, Kenya. Department of Psychiatry, University of Botswana, Private Bag, 00713 Gaborone, Botswana. ${ }^{3}$ Department of Psychiatry, University of Nairobi, Nairobi P.O. BOX 19676-00202, Kenya. ${ }^{4}$ Department of Psychiatry, University of Nairobi, Nairobi P.O. BOX 19676-00202, Kenya.

Received: 26 January 2018 Accepted: 7 June 2018

Published online: 18 June 2018

\section{References}

1. Substance Abuse and Mental Health Services Administration. Adverse Childhood Experiences: SAMHSA; 2016. Available from: https://www.samhsa. gov/capt/practicing-effective-prevention/prevention-behavioral-health/ adverse-childhood-experiences.

2. CDC. About Adverse Childhood Experiences. 2016; Available from: https:// www.cdc.gov/violenceprevention/acestudy/about_ace.html.

3. WHO. Global Health Risks: Mortality and burden of disease attributable to selected major risks. Bull World Health Organ. 2009;87:646. Available from: 
http://www.who.int/healthinfo/global_burden_disease/GlobalHealthRisks_ report full.pdf.

4. WHO. WHO $\mid$ Adverse Childhood Experiences International Questionnaire (ACE-IQ): WHO; 2014. Available from: http://www.who.int/violence_injury_ prevention/violence/activities/adverse_childhood_experiences/en/.

5. Felitti VJ, Anda RF, Nordenberg D, Williamson DF, Spitz AM, Edwards V, et al. Relationship of childhood abuse and household dysfunction to many of the leading causes of death in adults: The adverse childhood experiences (ACE) study. Am J Prev Med 1998 [cited 2017 Jun 22];14(4):245-58. Available from: http://linkinghub.elsevier.com/retrieve/pii/S0749379798000178.

6. National Scientific Council on the Developing Child. Excessive stress disrupts the architecture of the developing brain: working paper 3. Work Pap. 2014 $1-12$.

7. Jonson-Reid M, Kohl PL, Drake B. Child and adult outcomes of chronic child maltreatment. Pediatrics. 2012;129(5):839-45. Available from: http:// pediatrics.aappublications.org/content/129/5/839?sso=1\&sso_redirect_ count $=1$ \&nfstatus $=401$ \&nftoken $=00000000-0000-0000-0000$ $000000000000 \&$ nfstatusdescription $=$ ERROR\%3A+No+local+token.

8. Becker-Weidman A. Effects of early maltreatment on development: A descriptive study using the vineland adaptive behavior scales-II. Child Welfare. 2009;88(2):137-61. Available from: http://search.proquest.com/ docview/213806844?pq-origsite=gscholar.

9. Ndetei DM, Khasakhala L, Maru H, Pizzo M, Mutiso V, Ongecha-Owuor FA, et al. Clinical epidemiology in patients admitted at Mathari psychiatric hospital, Nairobi, Kenya. Soc Psychiatry Psychiatr Epidemiol. 2008;43(9):736-42.

10. Othieno CJ, Kathuku DM, Ndetei DM. Substance abuse in outpatients attending rural and urban health centres in Kenya. East Afr Med J. 2000; 77(11):592-595. [cited 2017 Jun 22] Available from: http://www.ajol.info/ index.php/eamj/article/view/46728.

11. Douglas KR, Chan G, Gelernter J, Arias AJ, Anton RF, Weiss RD, et al. Adverse childhood events as risk factors for substance dependence: Partial mediation by mood and anxiety disorders. Addict Behav. 2010;35(1):7-13. Available from: http://www.ncbi.nlm.nih.gov/pubmed/19720467.

12. Dube SR, Dong M, Chapman DP, Giles WH, Anda RF, Felitti VJ. Childhood abuse, neglect, and household dysfunction and the risk of illicit drug use: the adverse childhood experiences study. Pediatrics. 2003;111(3):564. Available from: http://pediatrics.aappublications.org/content/111/3/564?sso= 1\&sso_redirect_count $=1 \&$ nfstatus $=401 \&$ nftoken $=00000000-0000-0000$ 0000-000000000000\&nfstatusdescription=ERROR\%3A+No+local+token.

13. Oladeji BD, Makanjuola VA, Gureje O. Family-related adverse childhood experiences as risk factors for psychiatric disorders in Nigeria. $\mathrm{Br} J$ Psychiatry. 2010;196(3):186-91. Available from: http://bjp.rcpsych.org/ content/196/3/186.

14. Kabiru CW, Beguy D, Crichton J, Ezeh AC. Self-reported drunkenness among adolescents in four sub-Saharan African countries: associations with adverse childhood experiences. Child Adolesc Psychiatry Ment Health. 2010;4(1):17. Available from: http://www.capmh.com/content/4/1/17.

15. Pirard S, Sharon E, Kang SK, Angarita GA, Gastfriend DR. Prevalence of physical and sexual abuse among substance abuse patients and impact on treatment outcomes. Drug Alcohol Depend. 2005;78(1):57-64. Available from: http://www.ncbi.nlm.nih.gov/pubmed/15769558.

16. Easton CJ, Swan S, Sinha R. Prevalence of family violence in clients entering substance abuse treatment. J Subst Abuse Treat. 2000;18(1):23-8. Available from: http://www.sciencedirect.com/science/article/pii/S0740547299000197.

17. Palmer JA, Palmer LK, Williamson D. Childhood abuse as a factor in attrition from drug rehabilitation. Psychol Rep. 1995;76(3 Pt 1):879-82. Available from: http://prx.sagepub.com/lookup/doi/10.2466/pr0.1995.76.3.879.

18. Brown DW, Riley L, Butchart A, Meddings DR, Kann L, Harvey AP. Exposure to physical and sexual violence and adverse health behaviours in African children: results from the global school-based student health survey. Bull World Health Organ 2009:87:447-455. Available from: http://www.who.int/ bulletin/volumes/87/6/07-047423.pdf.

19. Norman RE, Byambaa M, De R, Butchart A, Scott J, Vos T. The long-term health consequences of child physical abuse, emotional abuse, and neglect: a systematic review and meta-analysis. Tomlinson M, editor, PLoS Med Public Library of Science; 2012; 9:e1001349. Available from: http://dx.plos. org/10.1371/journal.pmed.1001349.

20. Goodman ML, Grouls A, Chen CX, Keiser PH, Gitari S. Adverse childhood experiences predict alcohol consumption patterns among Kenyan mothers. Subst Use Misuse. 2017;52(5):632-8. Available from: https://doi.org/10.1080/ 10826084.2016.1245748.
21. World Health Organizsation. Adverse Childhood Experiences International Questionnaire; 2011. p. 4-8. Available from: http://www.who.int/violence_ injury_prevention/violence/activities/adverse_childhood_experiences/ global_research_network_may_2011.pdf.

22. WHO. ACE-IQ Guidance for Analysing; 2016. p. 1-6. Available from: http:// www.who.int/violence_injury_prevention/violence/activities/adverse_ childhood_experiences/guidance_for_analysing.pdf?ua=1.

23. Kazeem OT. A Validation of the Adverse Childhood Experiences Scale in Nigeria. 2015;5(11):2225-484. Available from: http:/www.iiste.org/Journals/ index.php/RHSS/article/viewFile/23421/24137.

24. Wingenfeld K, Schäfer I, Terfehr K, Grabski H, Driessen M, Grabe H, et al. The reliable, valid and economic assessment of early traumatization: first psychometric characteristics of the German version of the Adverse Childhood Experiences Questionnaire (ACE). Psychother Psychosom Medizinische Psychol. 2011;61(1):e10-4. Available from: http://www.ncbi.nIm. nih.gov/pubmed/20878600.

25. Heslop K, Ross C, Osmond B, Wynaden D. The alcohol smoking and substance involvement screening test (ASSIST) in an acute mental health setting. Int J Ment Health Addict. 2013;11(5):583-600.

26. Gryczynski J, Kelly SM, Mitchell SG, Kirk A, O'Grady KE, Schwartz RP. Validation and performance of the Alcohol, Smoking and Substance Involvement Screening Test (ASSIST) among adolescent primary care patients. Addiction. 2015;110(2):240-7. Available from: http://doi.wiley.com/ 10.1111/add.12767.

27. WHO. The alcohol, smoking and substance involvement screening test (ASSIST). 2010;97(6):1-74. Available from: http://doi.wiley.com/10.1111/j. 1360-0443.2007.02114.x.

28. WHO ASSIST Working Group. The Alcohol, Smoking and Substance Involvement Screening Test (ASSIST): development, reliability and feasibility. Addiction. 2002;97(9):1183-94. Available from: http://www.ncbi.nlm.nih.gov/ pubmed/12199834.

29. Rather YH, Bashir W, Ahmad Sheikh A, Aamin M, Arafat Zahgeer Y. Sociodemographic and clinical profile of substance abusers attending a regional drug de-addiction centre in chronic conflict area: Kashmir, India. Malaysian J Med Sci. 2013;20(3):31-8. Available from: http://www.ncbinlm.nih.gov/ pubmed/23966822.

30. Hauli KA, Ndetei DM, Jande MB, Kabangila R. The prevalence of substance use among psychiatric patients: the case study of Bugando Medical centre, Mwanza (northern Tanzania). Subst Abus. 2011;32(4):238-41. Available from: http://www.tandfonline.com/doi/abs/10.1080/08897077.2011.599253.

31. Almuneef $M$, Qayad M, Aleissa M, Albuhairan F. Adverse childhood experiences, chronic diseases, and risky health behaviors in Saudi Arabian adults: A pilot study. Child Abus Negl. 2014;38(11):1787-93. Available from: http://www.sciencedirect.com/science/article/pii/S0145213414002154.

32. Kessler RC, McLaughlin KA, Green JG, Gruber MJ, Sampson NA, Zaslavsky AM, et al. Childhood adversities and adult psychopathology in the WHO world mental health surveys. Br J Psychiatry. 2010;197(5):378-85. Available from: http://www.ncbinlm.nih.gov/pubmed/21037215.

33. Anda RF, Whitfield CL, Felitti VJ, Chapman D, Edwards VJ, Dube SR, et al. Adverse Childhood Experiences, Alcoholic Parents, and Later Risk of Alcoholism and Depression. Psychiatr Serv. 2002:53(8):1001-9. Available from: http://psychiatryonline.org/doi/abs/10.1176/appi.ps.53.8.1001.

34. Anda RF, Croft JB, Felitti VJ, Nordenberg D, Giles WH, Williamson DF, et al. Adverse Childhood Experiences and Smoking during Adolescence and Adulthood. JAMA. 1999;282(17):1652-8. Available from: http://jama. jamanetwork.com/article.aspx?doi=10.1001/jama.282.17.1652.

35. Ford ES, Anda RF, Edwards VJ, Perry GS, Zhao G, Li C, et al. Adverse childhood experiences and smoking status in five states. Prev Med (Baltim). 2011;53(3):188-93. Available from: http://www.sciencedirect.com/science/ article/pii/S0091743511002416

36. Duncan $A E, P h D$, Sartor CE, Ph D, Scherrer JF, Ph D, et al. The association between cannabis abuse and dependence and childhood physical and sexual abuse: evidence from an offspring of twins design. Addiction. 2009;103(6):990-7.

37. Alemu A, Moses J, Williams G, Strathearn L, Clavarino A, Kisely S. Substantiated childhood maltreatment and young adulthood cannabis use disorders : a pre-birth cohort study. Psychiatry Res. 2017;256(October 2016): 21-31. Available from: https://doi.org/10.1016/j.psychres.2017.06.017.

38. Widmann M, Warsame AH, Mikulica J, von Beust J, Isse MM, Ndetei D, et al. "Khat Use, PTSD and Psychotic Symptoms among Somali Refugees in Nairobi â€" A Pilot Study. Front Public Heal. 2014;2:71. Available from: http:// www.ncbi.nlm.nih.gov/pubmed/25072043. 
39. Anda RF, Brown DW, Felitti VJ, Bremner JD, Dube SR, Giles WH. Adverse Childhood Experiences and Prescribed Psychotropic Medications in Adults. Am J Prev Med. 2007;32(5):389-94. Available from: http://www.sciencedirect. com/science/article/pii/S0749379707000116.

40. Bader K, Schäfer V, Schenkel M, Nissen L, Schwander J. Adverse childhood experiences associated with sleep in primary insomnia. J Sleep Res. 2007; 16(3):285-96. Available from: http://doi.wiley.com/10.1111/j.1365-2869.2007. 00608.x.

Ready to submit your research? Choose BMC and benefit from:

- fast, convenient online submission

- thorough peer review by experienced researchers in your field

- rapid publication on acceptance

- support for research data, including large and complex data types

- gold Open Access which fosters wider collaboration and increased citations

- maximum visibility for your research: over $100 \mathrm{M}$ website views per year 